\title{
Are we able to reduce the mortality and morbidity of oral cancer; Some considerations
}

\section{Isaäc van der Waal}

VU University Medical Center (VUmc)/Academic Centre for Dentistry Amsterdam (ACTA) Department of Oral and Maxillofacial Surgery and Oral Pathology

Correspondence:

VU University Medical Center (VUmc)/Academic Centre for Dentistry Amsterdam (Acta)

Department of Oral and Maxillofacial Surgery and Oral Pathology

P.O. Box 7057

$1007 \mathrm{MB}$ Amsterdam

The Netherlands

i.vanderwaal@vumc.nl

Received: $10 / 05 / 2012$ Accepted: 22/05/2012

van der Waal I. Are we able to reduce the mortality and morbidity of oral cancer; some considerations. Med Oral Patol Oral Cir Bucal. 2013 Jan 1;18 (1):e33-7.

http://www.medicinaoral.com/medoralfree01/v18i1/medoralv18ilp33.pdf

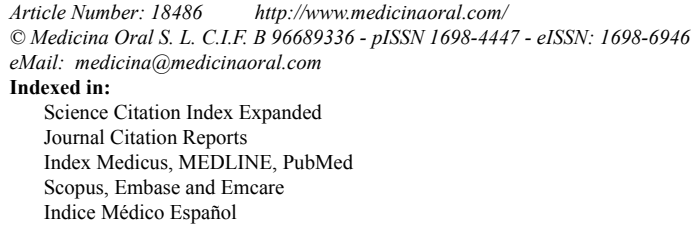

\begin{abstract}
Oral cancer makes up 1\%-2\% of all cancers that may arise in the body. The majority of oral cancers consists of squamous cell carcinomas. Oral cancer carries a considerable mortality rate, being mainly dependent on the stage of the disease at admission. Worldwide some $50 \%$ of the patients with oral cancer present with advanced disease. There are several ways of trying to diagnose oral cancer in a lower tumor stage, being 1) mass screening or screening in selected patients, 2) reduction of patients' delay, and 3) reduction of doctors' delay.

Oral cancer population-based screening ("mass screening") programs do not meet the guidelines for a successful outcome. There may be some benefit when focusing on high-risk groups, such as heavy smokers and heavy drinkers.

Reported reasons for patients' delay range from fear of a diagnosis of cancer, limited accessibility of primary health care, to unawareness of the possibility of malignant oral diseases. Apparently, information campaigns in news programs and TV have little effect on patients' delay. Mouth self-examination may have some value in reducing patients' delay.

Doctors' delay includes dentists' delay and diagnostic delay caused by other medical and dental health care professionals. Doctors' delay may vary from almost zero days up to more than six months.

Usually, morbidity of cancer treatment is measured by quality of life $(\mathrm{QoL})$ questionnaires. In the past decades this topic has drawn a lot of attention worldwide. It is a challenge to decrease the morbidity that is associated with the various treatment modalities that are used in oral cancer without substantially compromising the survival rate.

Smoking cessation contributes to reducing the risk of oral cancers, with a $50 \%$ reduction in risk within five years. Indeed, risk factor reduction seems to be the most effective tool in an attempt to decrease the morbidity and mortality of oral cancer.
\end{abstract}

Key words: Oral cancer, early diagnosis, quality of life. 


\section{Introduction}

Oral cancer makes up approximately $1 \%-2 \%$ of all cancers that may arise in the body. The great majority of oral cancers consists of squamous cell carcinomas. The remaining cancer types include malignant salivary gland tumors, sarcomas of the soft tissues and the jaw bones, melanoma, malignant odontogenic tumors, lymphoreticular malignancies, and metastases from tumors located elsewhere in the body.

Oral cancer carries a considerable mortality rate, being mainly dependent on the stage of the disease at admission. The five-year survival rate of stage I cancer, including the various subsites such as borders of the tongue, floor of the mouth, cheek, and gums amounts approximately $80 \%$, while the five-year survival of patients with advanced disease (stages III/IV) is approximately $20 \%$. Worldwide some $50 \%$ of the patients with oral cancer present with advanced disease (1). Early diagnosis, therefore, seems key. Even more important is to prevent oral cancer, which can be achieved mainly by cessation of heavy tobacco and alcohol consumption.

In a previous paper on early diagnosis of oral cancer it has been mentioned that the adjective "early" can be used in three ways, being 1) early in the process of carcinogenesis, 2) early in the meaning of a relatively small size of the cancer at the time of diagnosis, and 3) early in the meaning of a short interval between the time of symptoms and the time of diagnosis (2).

At present, there are no serological markers or any other laboratory studies that are helpful in detecting primary oral squamous cell carcinoma (OSCC) in a stage where there is no measurable tumor or precursor yet (3). Besides, displacing a diagnosis of cancer to an earlier stage of the carcinogenesis may prolong the survival time without actually influencing the time of death. This pitfall has been termed "lead-time-bias" (4).

As mentioned earlier, small stage OSCC carries a better survival rate than large stage OSCC. It is generally believed that patients with a short diagnostic delay (patients' and doctors' delay together) carry a better prognosis than those with a long diagnostic delay. However, the assumed better survival rate has not been confirmed in a few studies on this subject from the United Kingdom $(5,6)$. Furthermore, early detection and treatment of oral precancerous lesions, particularly leukoplakia and erythroplakia, may not truly prevent the future development of OSCC at the siteof the treated lesion or elsewhere in the oral cavity (7).

\section{Reducing the mortality of oral cancer by detec- tion oral cancer in a less advanced stage}

There are several ways of trying to diagnose oral cancer in a lower tumor stage, being 1) mass screening or screening in selected patients, 2) reduction of patients' delay, and 3) reduction of doctors' delay.
-Oral cancer population-based screening ("mass screening") programs do not meet the epidemiological guidelines for a successful outcome and are not considered to be cost-effective in its current forms (8). There may be some benefit when focusing screening programs on high-risk groups, such as heavy smokers and heavy drinkers (9), patients with previous cancer in the head and neck area (10), and patients with previous cancer outside the head and neck area (11).

In a study in Japan the results of oral screening as an integral part of general health screening in adults over 40 years of age have been reported (12). Some $26 \%$ of the population participated in the general health screening program and almost all of these entered the oral cancer screening program performed by dentists. The results of the oral screening are shown in (Table 1). These results do not allow to draw any conclusions about the

Table 1. Oral cancer screening as part of a free annual general health screening program in Japan (slightly modified) (12).

\begin{tabular}{|l|c|}
\hline \multicolumn{2}{|c|}{$\begin{array}{c}\text { Main findings in 19.000 } \\
\text { subjects }\end{array}$} \\
\hline Cancer & 9 \\
\hline Leukoplakia & 74 \\
\hline Erythroplakia & 4 \\
\hline Lichen planus & 102 \\
\hline Other & 518 \\
\hline Total & 707 \\
\hline
\end{tabular}

possible positive effect of the oral cancer screening program on morbidity and mortality. It merely shows that subjects who participate in a general health screening program almost without exception want to participate in an oral cancer screening program. Furthermore, no information has been provided in the Japanese study about the costs involved in the general health and oral cancer screening program.

-Reduction of patients' delay may reduce morbidity and may decrease the mortality rate. The average patients' delay in oral cancer diagnosis is approximately three months (13). Reported reasons for such delay range from fear of a diagnosis of cancer, limited accessibility of primary health care for patients with a low social economic status to, above all, unawareness of the possibility of malignant disease in case of a symptomatic oral lesion (14).

Apparently, information campaigns in news programs and TV have little effect on patients' delay (15). Few educational materials for the general public are available that are specifically directed to oral cancer and those that are available may be written at too a high grade level for the general public (16). In 2001 a leaflet on oral cancer directed at dental patients has been published (Table 2) (17). To the best of our knowledge the effectiveness of 
Table 2. Oral cancer: what to look for? A leaflet for dental patients (17).

- A color change in the oral tissues (whitish or red spots, for example)

- A lump, thickening, rough spot, crust or small eroded area

- A sore that bleeds easily or does not heal

- Pain, tenderness or numbness anywhere in the mouth or on the lips

- Difficulty in chewing, swallowing, speaking or moving the jaw or tongue

- Changes in the voice

- A change in the way your teeth fit together

In addition, watch for changes beyond the mouth that could signal oral cancer

- Drastic weight loss

- A lump or mass in your neck

this leaflet has not been examined yet. Rogers et al. reported the results of a survey among 71 oral and oropharyngeal cancer patients (18). A nonhealing ulcer or sore was reported as the most common first symptom; some $50 \%$ interpreted their symptoms as something minor, not being aware of oral cancer. Altogether, there is a lack of evidence that any public intervention has a measurable impact on oral cancer incidence and morbidity other than tobacco and alcohol consumption control (19).

-Mouth self-examination

In an Editorial by Sarode et al. the potential role of mouth self-examination has been emphasized as a method for reducing the morbidity and mortality rate of oral cancer (20). In a study in India, using a brochure describing the risk factors of oral cancer and precancer, and also showing the appearance of these lesions by photographs, 247 patients out of 8.000 patients who practiced mouth selfexamination reported to the clinics (21). The findings in these 247 patients have been presented in (Table 3). The

Table 3. Mouth self-examination in India (21).

- 9000 households received a brochure

- Directed at smokers and/or aged $>30$ years

- 22.000 eligible subjects

- 8000 practiced MSE

- 247 reported to the clinics for an oral examination

- seven (3\%) had oral cancer (six stage I)

- eighty-five (34\%) had precancerous lesions, including submucous fibrosis

- remaining participants had benign lesions or anatomical variations authors advised to further examine the possible value of mouth self-examination in a randomized controlled study, including much larger study groups and observing a follow-up period of at least ten years before being able to demonstrate a possibly significant reduction of the mortality rate. In a differently structured study, also conducted in India, the reliability of the results of mouth self-examination in some 34.000 persons were subsequently checked by health care workers (22). The results are shown in (Table 4). Apparently, mouth self-examination had a low sensitivity of $18 \%$, while the specificity was almost $100 \%$. A somewhat similar experience was observed in another study in the United Kingdom (23). -Reduction of doctors' delay in the diagnosis of oral cancer

Doctors' delay includes dentists' delay and also diagnostic delay caused by other medical and dental health care professionals. A dentist may not encounter an average of more than 5-10 patients with oral cancer during his professional life, while this number may be even less for medical practitioners. Also in view of the rather nonspecific symptoms and the diversity of clinical presentations of oral cancer, it should be no surprise that there is often a considerable delay in suspecting malignancy in case of oral cancer. Such delay may vary from almost zero days up to more than six months with a mean of three to five weeks $(13,24)$. Doctors' delay of more than five weeks occurs significantly more often in patients under the age of 40 years. Klosa et al. reported a discrepancy in the dentists opinions and practices in routine oral examination for cancerous and precancerous lesions (25).

Not surprisingly, it has been shown by Patton et al. that dental health professionals are more adequately trained to perform oral cancer examination than physicians (26). Physicians, indeed, felt a need for improvement of their oral examination skills. In a study from the United Kingdom medical professionals were questioned about possible barriers to conduct oral examinations for cancer (27). Barriers mentioned to perform such examinations were lack of training, lack of knowledge, lack of equipment, lack of time, and the notion that dentists are the ones who are primarily responsible for oral cancer detection. The latter notion was also mentioned in a study among primary health care professionals (28).

Table 4. Characteristics of oral lesions by self-examination and health worker examination ( $n=34.000)$ (22).

\begin{tabular}{|l|c|c|c|}
\hline \multicolumn{1}{|c|}{ Characteristics of lesions } & $\begin{array}{c}\text { Detected by SE } \\
\text { (number) }\end{array}$ & $\begin{array}{c}\text { Detected by HWs } \\
\text { (number) }\end{array}$ & $\begin{array}{c}\text { \% of lesions detected by SE } \\
\text { as compared to that of HWs }\end{array}$ \\
\hline White patch & 23 & 173 & 12.7 \\
\hline Red patch & 11 & 9 & 66.7 \\
\hline Non healing ulcer & 10 & 14 & 42.9 \\
\hline Difficulty in opening the mouth & 4 & 12 & 25.0 \\
\hline Other oral symptoms (e.g. burning sensation) & 6 & 11 & 18.2 \\
\hline Total & 54 & 219 & 17.8 \\
\hline
\end{tabular}


Reducing the morbidity of oral cancer treatment Morbidity of oral cancer treatment may be related to surgery, radiotherapy, chemotherapy and other treatment modalities and treatment related modalities, including dental rehabilitation. Usually, morbidity is measured by quality of life (QoL) questionnaires. Furthermore, QoL includes not only physical and mental health, but also factors such as family and leisure activities. The WHO has defined QoL as "Individual perceptions of their position in the context of the culture and value systems in which they live and in relation to their goals and concerns" (29).

In a study among 561 patients treated by surgery for oral and oropharyngeal cancer six groups were identified arranging from T1T2 oral cancer, no free flap, no RT to T3T4 oral cancer, free flap + RT and, as a separate group, oropharyngeal cancer (30). The items that have been scored are listed in table 5. The questionnaires have been completed at the time of admission and at 6 and 12 months after completion of treatment. Not surprisingly, the patients who do best are those with small oral cancers, not needing free-flap surgery and not having radiotherapy. This finding was confirmed in a study in Spain (31); in this latter study patients less than 65

Table 5. Items of a QoL questionnaire used in patients treated by primary surgery for oral and oropharyngeal cancer (30).

\begin{tabular}{|l|l|}
\hline - Pain & • Speech \\
- Appearance & • Shoulder \\
- Activity & - Taste \\
- Recreation & • Saliva \\
- Swallowing & - Mood \\
- Chewing & - Anxiety \\
\hline
\end{tabular}

years obtained higher QoL scores. De Wit et al. studied donor site morbidity of the fasciocutaneous radial forearm flap (32). Donor site morbidity measured by functional tests was limited but subjective self-ratings revealed complaints regarding cosmetics, sensibility and forearm disability.

In a study in the United Kingdom it was shown that cancer of the head and neck (HNC) has a serious impact on financial aspects of patients' life. In a survey in The Netherlands it was shown that HNC survivors return to work within six months after treatment (33); oral dysfunction, loss of appetite, deteriorated social functioning, and high levels of anxiety were barriers for HNC survivors to return to work after treatment. In a study by Borggreven et al. is was shown that comorbidity has a major impact on patients treated for HNC (34). In Verdonck's et al study is was shown that distress is often present in spouses and patients after treatment for HNC (35). Distress in patients was related to the presence of a feeding tube, speech and swallowing problems, less so- cial contacts, a passive style of coping, and nonexpression of emotions. Handschel et al. emphasized the impact of psychological treatment in HNC patients (36). Langendijk et al. reported on the late treatment-related toxicity on quality of life among patients with $\mathrm{HNC}$ treated with radiotherapy. It was concluded that the development of new radiation-induced delivery techniques should not only focus on reduction of the dose to the salivary glands, but also to anatomic structures that are involved in swallowing (37).

It is a challenge to decrease the morbidity that is associated with the various treatment modalities that are used in oral cancer without substantially compromising the survival rate. On the other hand, improving the survival rate by extended treatment may significantly increase the morbidity and, thereby, influence the quality of life in a negative way.

\section{Prevention}

It is obvious that cessation of tobacco and alcohol use results in a lower incidence of oral cancer. Smoking cessation contributes to reducing the risk of oral cancers, with a 50\% reduction in risk within five years (38); ten years after smoking cessation the risk approaches that for life-long nonsmokers.

There are numerous reports on cessation of smoking programs. An interesting overview of these studies is provided by Maillet et al (39). Tobacco cessation counseling can be performed by dentists and also by dental auxiliary personnel, such as dental hygienists (39). In Maillet's et al study, the results have not been very encouraging, as shown in table 6 . Only $2 \%$ of the patients stopped permanently using tobacco. The authors announced to improve their program and to again evaluate the results.

Table 6. Tobacco cessation counseling by dental hygienists. Responses to survey questions among 132 dental patients (39).

\begin{tabular}{|l|c|c|}
\hline Question & $\begin{array}{c}\text { Percent of } \\
\text { subjects who } \\
\text { replied yes }\end{array}$ & $\begin{array}{c}\text { Percent of } \\
\text { subjects who } \\
\text { replied no }\end{array}$ \\
\hline 1. Were you advised to quit tobacco usage? & $90 \%$ & $10 \%$ \\
\hline 2.Were you advised of the health risks associated with tobacco use? & $98 \%$ & $2 \%$ \\
\hline 3.Were information pamphlets provided to you? & $51 \%$ & $49 \%$ \\
\hline 4.Were you provided with strategies to assist in the quitting process? & $53 \%$ & $47 \%$ \\
\hline 5.After counseling, did you permanently quit using tobacco? & $2 \%$ & $98 \%$ \\
\hline 6.If not) Did you quit for any period of time? & $22 \%$ & $78 \%$ \\
\hline 7.Were you taught self-examination techniques? & $33 \%$ & $67 \%$ \\
\hline 8.(If yes) Do you do the self-examination? & $65 \%$ & $35 \%$ \\
\hline $\begin{array}{l}\text { 9.Was there any follow-up, by either a phone call or appointment } \\
\text { following your TCC*? }\end{array}$ & $8 \%$ & $92 \%$ \\
\hline
\end{tabular}

* Average quit time was 3.5 months.

\section{Conclusions}

Particularly risk factor reduction and perhaps also early detection of oral cancer and precancer will decrease the morbidity and mortality of oral cancer. 
There should be ways to increase the awareness of the public about oral cancer and precancer, including knowledge about the risk factors. At present, the results of mouth self-examination are somewhat disappointing. Mass screening for oral cancer is regarded not to be cost-effective. Instead, screening of selected high risk groups may be worth to perform in an attempt to diagnose oral cancer in an earlier tumor stage, thereby allegedly reducing the morbidity and mortality rate. Dentists and physicians should be continuously advised to attend programs that are directed at the early detection of oral cancer and precancer.

\section{Reference}

1. Warnakulasuriya S. Global epidemiology of oral and oropharyngeal cancer. Oral Oncol. 2009;45:309-16.

2. Van der Waal I, de Bree R, Brakenhoff R, Coebergh JW. Early diagnosis in primary oral cancer: is it possible. Med Oral Patol Oral Cir Bucal. 2011;16:e300-e305.

3. Mydlarz WK, Hennessey PT, Califano JA. Advances and Perspectives in the Molecular Diagnosis of Head and Neck Cancer. Expert Opin Med Diagn. 2010;4:53-65.

4. Patz EF, Goodman PC, Bepler G. Screening for lung cancer. N Engl J Med 2000;343:1627-33.

5. McGurk M, Chan C, Jones J, O'Regan E, Sherriff M. Delay in diagnosis and its effect on outcome in head and neck cancer. Br J Oral Maxillofac Surg. 2005;43:281-84.

6. Scott SE, Grunfeld EA, McGurk M. The idiosyncratic relationship between diagnostic delay and stage of oral squamous cell carcinoma. Oral Oncol. 2005;41:396-403.

7. Tradati N, Grigolat R, Calabrese L, Costa L, Giugliano G, Morelli F, et al. Oral leukoplakias: to treat or not. Oral Oncol. 1997;33:317-21.

8. Kujan O, Glenny AM, Duxbury J, Thakker N, Sloan P. Evaluation of screening strategies for improving oral cancer mortality: a Cochrane systematic review. J Dent Educ. 2005;69:255-65.

9. Sankaranarayanan R, Ramadas K, Thomas G, Muwonge R, Thara S, Mathew B, et al. Effect of screening on oral cancer mortality in Kerala, India: a cluster-randomised controlled trial. Lancet. 2005;365:1927-33.

10. Van der Waal I, de Bree R. Second primary tumours in oral cancer. Oral Oncol. 2010;46:426-8.

11. Dong C, Hemminki K. Second primary neoplasms in 633,964 cancer patients in Sweden, 1958-1996. Int J Cancer. 2001;93:155-61.

12. Nagao T, Warnakulasuriya S, Ikeda N, Fukano H, Fujiwara K, Miyazaki H. Oral cancer screening as an integral part of general health screening in Tokoname City, Japan. J Med Screen. 2000;7:203-8.

13. Peacock ZS, Pogrel MA, Schmidt BL. Exploring the reasons for delay in treatment of oral cancer. J Am Dent Assoc. 2008;139:1346-52.

14. Warnakulasuriya KA, Harris CK, Scarrott DM, Watt R, Gelbier $\mathrm{S}$, Peters TJ, et al. An alarming lack of public awareness towards oral cancer. Br Dent J. 1999;187:319-22.

15. Stahl S, Meskin LH, Brown LJ. The American Dental Association's oral cancer campaign: the impact on consumers and dentists. J Am Dent Assoc. 2004;135:1261-7.

16. Chung V, Horowitz AM, Canto MT, Siriphant P. Oral cancer educational materials for the general public: 1998. J Public Health Dent. 2000;60:49-52.

17. ADA Division of Communications. For the dental patient. Oral cancer. How to protect yourself. J Am Dent Assoc. 2001;132 Suppl:48S.

18. Rogers SN, Vedpathak SV, Lowe D. Reasons for delayed presentation in oral and oropharyngeal cancer: the patients perspective. $\mathrm{Br}$ J Oral Maxillofac Surg. 2011;49:349-53.

19. Torres-Pereira C. Oral cancer public policies: is there any evidence of impact? Braz Oral Res. 2010;24 Suppl 1:37-42.

20. Sarode SC, Sarode GS, Karmarkar S. Early detection of oral cancer: detector lies within. Oral Oncol. 2012;48:193-4.
21. Mathew B, Sankaranarayanan R, Wesley P, Krishnan-Nair M. Evaluation of mouth self-examination in the control of oral cancer. Br J Cancer. 1995;71:397-9.

22. Elango KJ, Anandkrishnan N, Suresh A, Iyer SK, Ramaiyer SK, Kuriakose MA. Mouth self-examination to improve oral cancer awareness and early detection in a high-risk population. Oral Oncol. 2011;47:620-4.

23. Scott SE, Rizvi K, Grunfeld EA, McGurk M. Pilot study to estimate the accuracy of mouth self-examination in an at-risk group. Head Neck. 2010;32:1393-401.

24. Jovanovic A, Kostense PJ, Schulten EA, Snow GB, van der Waal I. Delay in diagnosis of oral squamous cell carcinoma; a report from The Netherlands. Eur J Cancer B Oral Oncol. 1992;28B:37-8.

25. Klosa K, Wiltfang J, Wenz HJ, Koller M, Hertrampf K. Dentists' opinions and practices in oral cancer prevention and early detection in Northern Germany. Eur J Cancer Prev. 2011;20:313-9.

26. Patton LL, Ashe TE, Elter JR, Southerland JH, Strauss RP. Adequacy of training in oral cancer prevention and screening as self-assessed by physicians, nurse practitioners, and dental health professionals. Oral Surg Oral Med Oral Pathol Oral Radiol Endod. 2006;102:758-64.

27. Wade J, Smith H, Hankins M, Llewellyn C. Conducting oral examinations for cancer in general practice: what are the barriers. Fam Pract. 2010;27:77-84

28. Macpherson LMD, McCann MF, Gibson J, Binnie VI, Stephen $\mathrm{KW}$. The role of primary healthcare professionals in oral cancer prevention and detection. Br Dent J. 2003;195:277-81.

29. Whoqol-Bref. Introduction, administration, scoring and generic vesion of the assessment. $<$ http:www who int/mental_health/media/ en $/ 67 \mathrm{pdf}>.1996$.

30. Rogers SN, Scott J, Chakrabati A, Lowe D. The patients' account of outcome following primary surgery for oral and oropharyngeal cancer using a 'quality of life' questionnaire. Eur J Cancer Care (Engl). 2008;17:182-8.

31. López-Jornet P, Camacho-Alonso F, López-Tortosa J, Palazon Tovar T, Rodríguez-Gonzales MA. Assessing quality of life in patients with head and neck cancer in Spain by means of EORTC QLQ-C30 and QLQ-H\&N35. J Craniomaxillofac Surg. 2012;40:614-20.

32. de Witt CA, de Bree R, Verdonck-de Leeuw IM, Quak JJ, Leemans CR. Donor site morbidity of the fasciocutaneous radial forearm flap: what does the patient really bother. Eur Arch Otorhinolaryngol. 2007;264:929-34.

33. Verdonck-de-Leeuw I, van Bleek WJ, Leemans CR, de Bree R. Employment and return to work in head and neck cancer survivors. Oral Oncol. 2010;46:56-60.

34. Borggreven PA, Verdonck-de Leeuw I, Muller MJ, Heiligers ML, de Bree R, Aaronson NK, et al. Quality of life and functional status in patients with cancer of the oral cavity and oropharynx: pretreatment values of a prospective study. Eur Arch Otorhinolaryngol. 2007;264:651-7.

35. Verdonck-de Leeuw I, Eerenstein SE, van der Linden MH, Kuik DJ, de Bree R, Leemans CR. Distress in spouses and patients after treatment for head and neck cancer. Laryngoscope. 2007;117:238-41.

36. Handschel J, Naujoks C, Hofer M, Kruskemper G. Psychological aspects affect quality of life in patients with oral squamous cell carcinomas. Psychooncology. 2012 Feb 20. doi: 10.1002/pon.3052. [Epub ahead of print].

37. Langendijk JA, Doornaert P, Verdonck-de LI, Leemans CR, Aaronson NK, Slotman BJ. Impact of late treatment-related toxicity on quality of life among patients with head and neck cancer treated with radiotherapy. J Clin Oncol. 2008;26:3770-3776.

38. Samet JM. The health benefits of smoking cessation. Med Clin North Am. 1992;76:399-414.

39. Maillet JP, Tax CL, Neish NR, Denny AL. Evaluation of outcomes for tobacco cessation counseling in the Dalhousie University dental hygiene curriculum. J Dent Educ. 2010;74:311-7. 